\title{
In Vitro Comparison of Modes of Failures among Titanium and One- and Two-piece Zirconia Abutment under Static Load
}

\author{
Fawaz Alqahtani ${ }^{1, \odot} \quad$ Mohammed AlAmar ${ }^{2}$ \\ ${ }^{1}$ Department of Prosthodontics, College of Dentistry, Prince Sattam \\ Bin Abdulaziz University, Al-Kharj, Saudi-Arabia \\ 2Department of Prosthodontics, Ministry of Health, Riyadh, \\ Saudi Arabia
}

\begin{abstract}
Address for correspondence Fawaz Alqahtani, BDS, MDS, FACP, DABP, Department of Prosthodontics, College of Dentistry, Prince Sattam Bin Abdulaziz University, Al-Kharj 11942, Saudi-Arabia (e-mail: implantologist@yahoo.com).
\end{abstract}

Eur J Dent 2020;14:157-160

\begin{abstract}
Keywords

- fracture resistance

- mode of fracture

- static load

- titanium

- zirconia
\end{abstract}

Objectives The objective was to assess modes of failures under static load (SL) among titanium ( $\mathrm{Ti}$ ) and one- and two-piece zirconia abutment $(\mathrm{ZA})$ in vitro.

Materials and Methods The Ti abutments were digitally scanned for the fabrication of the one- and two-piece zirconia abutment specimens. This was done to standardize the design of the one-piece abutment and make it the blueprint of the Ti abutment. Twenty-one implant abutments and 21 implant replicas were categorized into three groups as follows: group 1 (Titanium group), group 2 (one-piece ZA group), and group 3 (two-piece ZA group). A 250K-cycle, linear fatigue-load, reaching 10 to 210 Newton $(\mathrm{N})$, was put on all specimens using an all-electric dynamic test instrument and the specimens were loaded until fracture.

Statistical Analysis Assessment of mode of fracture among the groups was done visually. Significance was based below 0.05 .

Results Screw fracture $(n=7)$ and abutment bending at the apical part $(n=7)$ occurred in the Ti group. In the one-piece zirconia group, screw and abutment fractures occurred in seven and seven cases, respectively. In the two-piece zirconia group, screw fracture $(n=7)$ above the Ti zirconia junction (transgingival segment) and abutment fracture $(n=7)$ were determined as the failure modes.

Conclusion In conclusion, all abutments underwent failures under SL in vitro; and the mode of failure modes varied among the different abutment designs used.

\section{Introduction}

Abutment for titanium (Ti) implants are usually fixed using an internal or external connection. ${ }^{1,2}$ With advancements in clinical implant dentistry and related research, zirconia implants were introduced, in which the internal connection can be achieved by the one- or two-piece zirconia abutments (ZAs). ${ }^{1}$ Studies ${ }^{3-5}$ have assessed the load-to-fracture (LTF) values regarding the one-piece and 2-piece ZAs. Invitro results by Gehrke et al $^{3}$ showed that the one-piece ZA has a lower fracture load than two-piece ZAs. These results are comparable to those reported by Chun et al ${ }^{4}$ Nevertheless, controversial results have also been reported. ${ }^{6} \mathrm{Kim}$ and coworkers assessed ${ }^{7}$ the fracture load of one-piece and twopiece ZA under static load (SL). The study ${ }^{7}$ results showed no difference in maximum-load-capacity for one-piece and two-piece ZAs.

In the study by Brodbeck $\mathrm{U},{ }^{8}$ destructive impact of zirconia on implants' external hexagon were reported. Moreover, a pilot study by Klotz and associates ${ }^{9}$ assessed the wear of Ti and ZAs under a cyclic load. According to the results of this investigation, implants with zirconia-abutments demonstrate a higher wear rate as compared with Ti-based implant abutments. ${ }^{9}$ Damages of this sort at the region of the junction between the abutment and implant can potentially 
cause implant prosthesis fracture. Although enough evidence exists in indexed literature regarding the fracture strength of Ti and zirconia implants ${ }^{10-12}$, there is a dearth of published data regarding the mode of fracture of one- and two-piece zirconia implants. Kammermeier et a ${ }^{12}$ experimentally measured fracture resistance (FR) of two-piece-zirconia implant systems and observed that the FR of 2-piece zirconia implant systems was poorer as compared with one-piece zirconia implants. Nevertheless, the precise mode of fracture of zirconia implants remained unclear in this study. ${ }^{12}$ In a recent scanning electron microscopy (SEM) based in-vitro study, Moris et $\mathrm{al}^{13}$ investigated the fracture modes of TI and customized and noncustomized ZAs. The SEM results showed that the Ti abutments underwent a plastic deformation, whereas the ZAs fractured following application of SL. Moreover, in ZAs, the fracture occurred underneath the platform of the implant in the zone between the abutment and implant, which propagated to the abutments' internal surface. ${ }^{13}$ Furthermore, in the study by Kim et al, ${ }^{7}$ modes of failure of three types of ZAs were assessed. The results showed that there was a variation in the modes of fracture of the 3 ZAs used. ${ }^{7}$ There is no published literature that has compared the mode of fracture among Ti and one- and two-piece ZAs under SL. Our hypothesis is that the modes of fracture under SL are comparable among the Ti and one-piece and two-piece ZAs.

The objective of this comparative in-vitro experiment was to assess the modes of failures among Ti and one- and twopiece ZAs under SL.

\section{Materials and Methods}

\section{Fabrication of Test Specimens}

The one- and two-piece ZA specimens were fabricated via scanning the Titanium abutment using a scanner (NobelProcera 2G Scanner; CH-8058 Zürich-Flughafen, Switzerland). This was done to standardize the design of the one-piece abutment and make it as a blueprint of the Ti abutment.

\section{Grouping}

Twenty-one implant abutments and 21 implant replicas (NobleReplace) were equally divided into three groups as follows: group 1 (Titanium group), group 2 (one-piece ZA group), and group 3 (two-piece ZA group).

\section{Specimen Preparation for Fatigue Test}

The implant replicas were mounted on a metal jig, which was machined from stainless steel (SS) into two-part with engraved pins to receive one implant replica. A metal base was fabricated to hold the metal jig with secure screws to fix the position of specimen. The top of the base had a $135^{\circ}$ inclination to the load application axis and the bottom was attached to a machine table. The load applicator was fabricated of SS and shaped to simulate the lower central incisor edge. The abutment was screwed into the implant replica at $35 \mathrm{Ncm}$ using an implant motor console (Digital Torque; W\&H implantMED, Bürmoos, Austria). Retightening of the screw of the abutment was done again after 10 minutes. ${ }^{14}$ The implant abutment (1) Titanium, (2) one-piece zirconia, and (3) twopiece zirconia were mounted on the metal jig. A $250 \mathrm{~K}$-cycle linear fatigue load, reaching from 10 to $210 \mathrm{~N}$, was enforced on all specimens using an all-electric-dynamic-test instrument, and the specimens were loaded until fracture.

\section{Assessment of Mode of Fracture}

Visual assessment of mode of fracture was done by an investigator whose intraexaminer kappa score was 0.92 .

\section{Statistical Analysis}

Using a computer-based software (SPSS, Version 20, Chicago, I.L., USA), group comparisons were performed using utilizing Kolmogorov and Shapiro tests. Levene's test was performed to determine variances' homogeneity. $P$-values below the value of 0.05 were an indicator of statistical significance. Power-based calculations were done as recommended by Gehrke et al. ${ }^{3}$ Based on the results of a pilot investigation, it was estimated that with the use of seven abutments per group, the study would attain a power of $80 \%$ to notice differences among the mean with an $\alpha$ of 0.05 .

\section{Results}

\section{Modes of Fracture}

Screw fracture $(n=7)$ and abutment bending at the apical part $(n=7)$ occurred in the Ti group. In the one-piece zirconia group, screw and abutment fractures occurred in seven and seven cases, respectively. In the two-piece zirconia group, screw fracture $(n=7)$ above the Ti zirconia junction (transgingival segment) and abutment fracture $(n=7)$ were determined as the failure modes ( $\boldsymbol{- T a b l e ~} \mathbf{1}$ ). Modes of failure of $\mathrm{Ti}$ and one-piece and two-piece ZAs are illustrated in -Fig. $\mathbf{1}$.

\section{Discussion}

The current in vitro results showed that Ti and one- and twopiece ZAs exhibit different modes of failure under SL. Our results clearly demonstrated that under a SL, screw fractures

Table 1 Failure mode for Titanium and 1- and 2-piece zirconia abutment groups

\begin{tabular}{|l|l|l|l|l|}
\hline \multirow{2}{*}{ Study groups } & \multicolumn{4}{|c|}{ Mode of failure } \\
\cline { 2 - 5 } & Screw fracture $(\boldsymbol{n})$ & Screw bending $(\boldsymbol{n})$ & Abutment fracture $(\boldsymbol{n})$ & Abutment bending $(\boldsymbol{n})$ \\
\hline Titanium group & 7 & 0 & 0 & 7 \\
\hline One-piece zirconia & 7 & 0 & 7 & 0 \\
\hline Two-piece zirconia & 0 & 7 & 7 & 0 \\
\hline
\end{tabular}

Note: $n=$ number of failures 


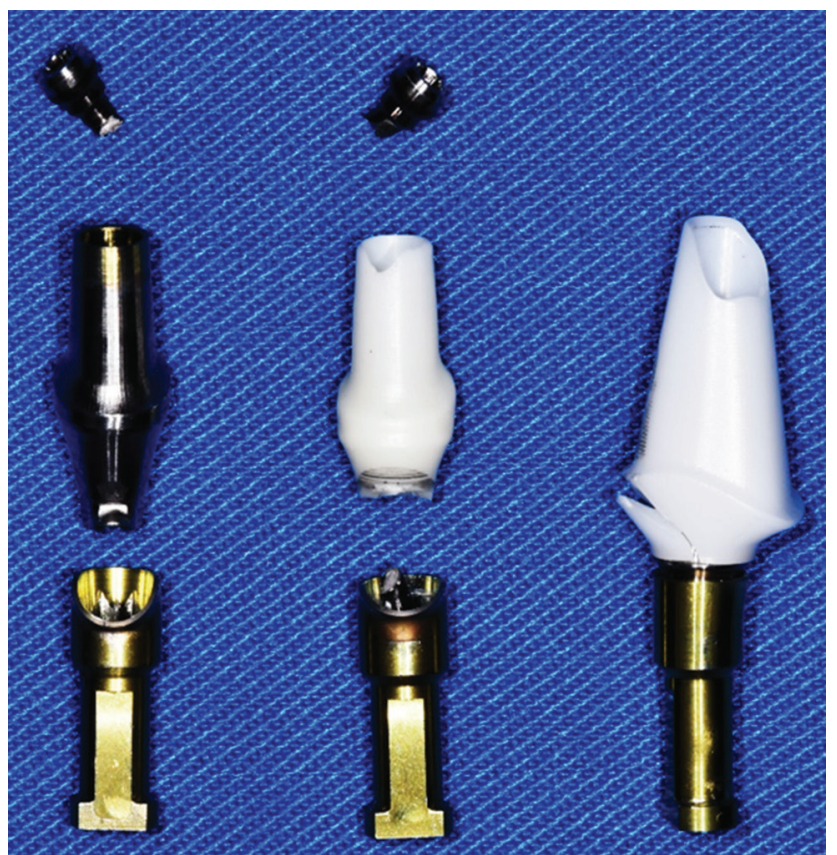

Fig. 1 An illustration of various fracture modes observed in the titanium and 1- and 2-piece zirconia abutment groups.

and bending of abutment occurred in Ti abutments; whereas, screw bending and abutment fracture were the prevalent modes of fracture of two-piece ZAs. On the contrary, the modes of fracture of one-piece ZAs were fracture of screw and abutment. From these results, it is obvious that that the proposed hypothesis is rejected. From a clinical perspective, the present in vitro results emphasize that the classical risk factors, such as bad oral hygiene status, use of tobacco containing products, and immunosuppression (as seen in patients with long-standing hyperglycemia), are not the only causes of failure of implants ${ }^{15-17}$, and high-end occlusal forces can also create complications (such as fracture induction at the implant abutment interface) which, if left untreated and not dealt with in a timely manner, may lead to peri-implant diseases and even implant failure. Nevertheless, it is clinically exigent to determine a minimum threshold value of biting force, which may stringently reflect the occlusal masticatory forces. It has been reported that habits such as bruxism are risk factors of abutment fracture in patients with dental implants. ${ }^{18}$ In this regard, there is a possibility that Ti, and one- and two-piece ZAs are more susceptible to display modes of fractures comparable to the patterns reported in the present in-vitro investigation. It is speculated that individuals demonstrating high-biting forces and simultaneously exposed to risk factors of implant failure (such as those mentioned above) more often display Ti and one- and two-piece ZA fractures compared with unexposed patients with normal biting forces. To the best of our knowledge, this hypothesis is yet to be assessed.

In our experimental study, a $250 \mathrm{~K}$ cyclic load was utilized to expose specimens to fatigue, using forces which ranged from 10 to $210 \mathrm{~N}$ to simulate a 1-year human chewing function. ${ }^{19}$ The specimens were mounted on a heavy SS jig with 135p inclination to the load application axis to simulate the clinical inclination between the upper and lower central incisor. The load applicator was especially shaped to simulate the shape of the edge of central incisors located in the mandible. Fatigue and load fracture tests were performed purely on abutments and all other parameters, such as porcelain-based ceramic crowns that are clinically related with the assembly, were eliminated. This was done to minimize confounding factors. In case, crowns were placed in the abutments, then crown-cement interface might have tolerated higher forces before failure due to its stress shielding mechanism, thereby biasing the recorded LTF values. ${ }^{6}$ Implant analogues were made from SS, instead of Ti, and were used in our experimental study. The replica made from SS bears higher forces before failure than titanium-fabricated implants. Furthermore, the replica made from SS eradicates the confounding variable that could have influenced our outcomes. ${ }^{20}$ The SS-based implant does not have the same resilience as bone and this could have dissipated a portion of the loading stress.

It is also pertinent to mention that variations in the mode of fracture among the Ti and one- and two-piece ZAs could be credited to varying abutment systems, direction of the load, and preceding the LTF test without conducting the fatigue test. Alqahtani and Flinton ${ }^{6}$ tested fracture loads of zirconia implant abutments with varying planes of preparation. Although modes of fracture remained unaddressed in their study, there is a likelihood that mode of failures varied between the study groups. It can be speculated that the difference in mean of the LTF load is due to different implant systems and abutment thicknesses.

One limitation of our experimental study is that the results were based on in-vitro observation of modes of fracture of various implant abutment connections under SL. For instance, nocturnal bruxism induces high occlusal forces $^{21}$, and is therefore a risk factor of prosthesis fracture. It seems challenging to determine the minimum SL value required to induce fracture of the various abutments used in the present study. Further studies are needed in this context. There is a likelihood that the mode of fracture of one- and two-piece zirconia abutments varies among patients with bruxism. Further studies are required to test this hypothesis.

\section{Conclusion}

All abutments underwent failures under SL in vitro, and the mode of failure varied according to the different abutment designs used.

\section{Authors' Contributions}

Fawaz Alqahtani designed and supervised the study and wrote the manuscript. Mohammed AlAmar performed the experiments and wrote the results. Mohammed AlAmar and Fawaz Alqahtani read and revised the manuscript prior to submission. 


\section{Conflict of Interest}

None declared.

\section{References}

1 Sailer I, Asgeirsson AG, Thoma DS, et al. Fracture strength of zirconia implant abutments on narrow diameter implants with internal and external implant abutment connections: A study on the titanium resin base concept. Clin Oral Implants Res 2018;29(4):411-423

2 Pereira PHS, Amaral M, Baroudi K, Vitti RP, Nassani MZ, Silva-Concílio LRD. Effect of implant platform connection and abutment material on removal torque and implant hexagon plastic deformation. Eur J Dent 2019;13(3):349-353

3 Gehrke P, Johannson D, Fischer C, Stawarczyk B, Beuer F. In vitro fatigue and fracture resistance of one- and two-piece CAD/CAM zirconia implant abutments. Int J Oral Maxillofac Implants 2015;30(3):546-554

4 Chun HJ, Yeo IS, Lee JH, et al. Fracture strength study of internally connected zirconia abutments reinforced with titanium inserts. Int J Oral Maxillofac Implants 2015;30(2):346-350

5 Qasim TQ, El-Masoud BM, Laban AMA. The effect of resistance grooves on the fracture toughness of zirconia-based crowns from mono and cyclic loading. Eur J Dent 2018;12(4):491-495

6 Alqahtani F, Flinton R. Postfatigue fracture resistance of modified prefabricated zirconia implant abutments. J Prosthet Dent 2014;112(2):299-305

7 Kim JS, Raigrodski AJ, Flinn BD, Rubenstein JE, Chung KH, Mancl LA. In vitro assessment of three types of zirconia implant abutments under static load. J Prosthet Dent 2013;109(4):255-263

8 Brodbeck U. The ZiReal post: a new ceramic implant abutment. J Esthet Restor Dent 2003;15(1):10-23, discussion 24

9 Klotz MW, Taylor TD, Goldberg AJ. Wear at the titanium-zirconia implant-abutment interface: a pilot study. Int J Oral Maxillofac Implants 2011;26(5):970-975

10 Elsayed A, Wille S, Al-Akhali M, Kern M. Effect of fatigue loading on the fracture strength and failure mode of lithium disilicate and zirconia implant abutments. Clin Oral Implants Res 2018;29(1):20-27
11 Elsayed A, Wille S, Al-Akhali M, Kern M. Comparison of fracture strength and failure mode of different ceramic implant abutments. J Prosthet Dent 2017;117(4):499-506

12 Kammermeier A, Rosentritt M, Behr M, Schneider-Feyrer $\mathrm{S}$, Preis V. In vitro performance of one- and two-piece zirconia implant systems for anterior application. J Dent 2016;53:94-101

13 Moris ICM, Chen YC, Faria ACL, Ribeiro RF, Fok AS, Rodrigues RCS. Fracture loads and failure modes of customized and non-customized zirconia abutments. Dent Mater 2018;34(8):e197-e204

14 Siamos G, Winkler S, Boberick KG. Relationship between implant preload and screw loosening on implant-supported prostheses. J Oral Implantol 2002;28(2):67-73

15 Akram Z, Javed F, Vohra F. Effect of waterpipe smoking on peri-implant health: A systematic review and meta-analysis. J Investig Clin Dent 2019;10(3):e12403

16 Al Amri MD, Kellesarian SV, Al-Kheraif AA, Malmstrom $\mathrm{H}$, Javed F, Romanos GE. Effect of oral hygiene maintenance on $\mathrm{HbA1c}$ levels and peri-implant parameters around immediately-loaded dental implants placed in type-2 diabetic patients: 2 years follow-up. Clin Oral Implants Res 2016;27(11):1439-1443

17 Javed F, Romanos GE. Impact of diabetes mellitus and glycemic control on the osseointegration of dental implants: a systematic literature review. J Periodontol 2009;80(11):1719-1730

18 Al-Almaie S. Management of broken dental implant abutment in a patient with bruxism: a rare case report and review of literature. Contemp Clin Dent 2017;8(3):485-489

19 Wiskott HW, Nicholls JI, Belser UC. Stress fatigue: basic principles and prosthodontic implications. Int J Prosthodont 1995;8(2):105-116

20 Adatia ND, Bayne SC, Cooper LF, Thompson JY. Fracture resistance of yttria-stabilized zirconia dental implant abutments. J Prosthodont 2009;18(1):17-22

21 Alkan A, Bulut E, Arici S, Sato S. Evaluation of treatments in patients with nocturnal bruxism on bite force and occlusal contact area: a preliminary report. Eur J Dent 2008;2(4):276-282 